\title{
Scheduled service versus personal transportation: The role of distance
}

\author{
Volodymyr Bilotkach ${ }^{\mathrm{a}, 1}$, Xavier Fageda ${ }^{\mathrm{b}, 2}$, Ricardo Flores-Fillol ${ }^{\mathrm{c}, *}$ \\ a Department of Economics, University of California-Irvine, 3151 Social Science Plaza, Irvine, CA 92796, USA \\ b Department of Economic Policy, Universitat de Barcelona, Avinguda Diagonal 690, 08034 Barcelona, Spain \\ c Department of Economics, Universitat Rovira i Virgili, Avinguda de la Universitat 1, 43204 Reus, Spain
}

\section{A R T I C L E I N F O}

Article history:

Received 23 December 2008

Received in revised form 26 May 2009

Accepted 29 September 2009

Available online 9 October 2009

\section{JEL classification:}

L13

L93

Keywords:

Short-haul routes

Long-haul routes

Flight frequency

Distance

\begin{abstract}
A B S T R A C T
This paper presents a theoretical and empirical analysis of the relationship between frequency of scheduled transportation services and their substitutability with personal transportation (using distance as a proxy). We study the interaction between a monopoly firm providing a high-speed scheduled service and private transportation (i.e., car). Interestingly, the carrier chooses to increase the frequency of service on longer routes when competing with personal transportation because by providing higher frequency (at extra cost) it can also charge higher fares which can boost its profits. However, in line with the results of earlier studies, frequency decreases for longer flights when driving is not a viable option. An empirical application of our analysis to the European airline industry confirms the predictions of our theoretical model.
\end{abstract}

(c) 2009 Elsevier B.V. All rights reserved.

\section{Introduction}

A problem faced by companies providing scheduled transportation (airlines, railway companies, etc.) is that it is impossible to achieve the level of mobility offered by the use of a private vehicle. Customers traveling by car do not have to bear a schedule delay cost inherent to the limited choice of departure times that characterizes scheduled services. However, providers of scheduled transportation can make their product more attractive when competing with consumers' personal vehicles by offering high-frequency, high-speed services. There are also cases in which driving is not a relevant alternative (when the distance between the endpoints is particularly long), and in this case a scheduled carrier has to make its service attractive with respect to the option of not traveling at all. These two problems may have different solutions; however, no differentiation between them has been offered in the literature.

This paper fills this void by examining fare and frequency choices of a monopoly provider of scheduled transportation services. We compare the case where the customer's next best available alternative is driving with the scenario where driving is not a relevant option (i.e.,

\footnotetext{
* Corresponding author. Tel.: +34 977759851; fax: +34 977759810.

E-mail addresses: vbilotka@uci.edu (V. Bilotkach), xfageda@ub.edu (X. Fageda), ricardo.flores@urv.cat (R. Flores-Fillol).

${ }^{1}$ Tel.: +1 9498245192; fax: +19498242182.

${ }^{2}$ Tel.: +34 934039721; fax: +34 934024573 .
}

it is a dominated alternative). The model yields testable predictions regarding frequency-distance relationships, which we put to the test using data from the European airline industry (where services are provided by a single carrier on over $60 \%$ of airport-pair markets).

In the theoretical part, we model a carrier (which we will consider to be an airline, although the analysis is easily applicable to highspeed rail as well) choosing fares and frequency of services, given that it enjoys an exogenous advantage in terms of higher speed of service than the private vehicle. This part builds on Brueckner (2004), Brueckner and Flores-Fillol (2007) and Bilotkach (2009). Brueckner (2004) considers a monopoly airline's network choice, incorporating decisions concerning frequency in the model. Brueckner and FloresFillol (2007) use this framework to analyze fare and frequency choices in duopoly markets. Finally, Bilotkach (2009) introduces a valuation of time similar to the one we use here in a model of airlines' network choice.

We find that the monopolist's choice crucially depends on whether driving is a dominated option or not. The carrier will reduce the frequency of service for longer trips when driving is dominated but, more interestingly, the relationship between frequency and distance may reverse when driving is not dominated and carriers compete with personal transportation.

Our result is explained by a trade-off between two forces. First, the provider of scheduled transportation services will always incur an extra cost when increasing frequency. Indeed, higher frequency implies additional fixed costs and reduces the opportunity of exploiting 
density economies which, in the case of airlines, arise from the use of bigger aircraft at high load factors. Second, an increase in distance may boost the demand for high-speed scheduled transportation services on short-haul routes where the use of personal vehicles is a relevant option for travelers. This is because an increase in distance makes the high-speed transportation mode more competitive and so providers of scheduled transportation services are able to increase frequency and charge higher fares.

On short-haul routes, our theoretical model shows that the positive effect of distance on frequency derived from charging higher fares outweighs the negative effect derived from incurring extra costs. This explains the main result of our analysis: the positive relationship between frequency and distance on routes where personal transportation is a relevant option. However, on long-haul routes where driving is a dominated option, an increase in distance does not necessarily imply an increase in the demand for scheduled services. Hence, we can expect a negative relationship between frequency and distance since the provider of scheduled services tries to minimize costs (and avoid potential travelers staying at home). Finally, from the perspective of the social optimum, we find that a monopoly carrier provides lower frequency of service than is socially optimal and the number of passengers making use of the scheduled transportation services is inefficiently low (as is usual for models of this kind).

Our model relates to the issue of intermodal competition and choice of transport mode. In this vein, Combes and Linnemer (2000) consider a model à la Hotelling in which two transportation modes compete (car and airplane) when a new infrastructure is built. More recently, Cantos-Sánchez et al. (2009) study alternative regulatory regimes in a model of intermodal competition and suggest an empirical application to the Spanish market. The issue of mode substitution and its effects has also been discussed, for example by Bel (1997), González-Savignat (2004), Janic (2003) and López-Pita and Robusté (2004). Some studies on choice of transport mode conclude that commuters mostly consider frequency of service (and more generally convenience of service) as one of the factors determining their elasticity (Voith, 1997 and Asensio, 2002); or the impact of urban transit projects (Baum-Snow and Kahn, 2000). Since with longer distances scheduled services become more attractive than personal transportation, due to their higher speed, we study how the monopolist's choice changes as the substitutability between the two transportation options increases.

We test the predictions of our theoretical model concerning the relationship between the length of haul and frequency using data on annual frequencies at the airline-route level. Our sample includes about 900 routes that link the ten largest airports in Europe with other European destinations (EU27+Switzerland and Norway) in the period 2006-2007. The empirical application examines the relationship between airlines' frequency choices and distance controlling for demand shifters at the route level, the attractiveness of air transport with respect to cars, the intensity of competition and airline attributes. A spline regression that shows the relationship between frequency and distance in our dataset makes it advisable to differentiate between routes shorter and longer than around $500 \mathrm{~km}$ ( 311 miles). Interestingly, the empirical application shows that airlines' frequency increases with distance for short-haul routes. In contrast, frequency decreases with distance for long-haul routes. Thus, the predictions of the theoretical model are confirmed. As expected, frequency increases with demand (captured by several variables) and with better airport access. We also find that airlines compete aggressively in frequency of service, low-cost carriers provide lower quality products, and airport presence strongly influences the number of flights that airlines offer on the routes served.

Previous empirical work has analyzed the determinants of airlines' flight frequency. Borenstein and Netz (1999) and Salvanes et al. (2005) find that airlines cluster the departure times of flights when competition increases in their studies for the US and Norway, respectively.
Our empirical application is more closely related to the studies by Pai (in press) and Wei and Hansen (2007). Pai (in press) estimates the determinants of flight frequency in the US airline market, observing a decreasing relationship between frequency and distance. From a different perspective, Wei and Hansen (2007) develop an application for three game-theoretic models of airline choices, obtaining that frequency on long-haul routes is less than on short-haul routes. These findings are in line with our results when driving is a dominated option. Thus, although these two previous studies adequately explain the relationship between frequency and distance on long-haul routes, our results suggest that the applicability of their findings to short-haul markets is limited. ${ }^{3}$

To sum up, the main contribution of this paper is to point out that the relationship between frequency choices and distance depends crucially on the presence of personal transportation, a finding identified theoretically and tested empirically for the European airline industry. Thus, the distance between endpoints in city-pair markets constitutes a potentially important factor to be considered when analyzing scheduled transportation services.

The plan of the paper is as follows. Section 2 presents the model and the equilibrium and compares the equilibrium outcome with the social optimum. An empirical application to the European airline market is provided in Section 3 and a brief conclusion closes the paper. All the proofs are provided in the Appendix.

\section{The model}

Our model is based on indirect utilities of heterogeneous travelers choosing between scheduled services and personal transport. We consider an air carrier as the provider of scheduled services, for the purpose of exposition, but other modes of transportation (in particular, the high-speed train) can easily fit into our framework.

The model combines elements of Brueckner's (2004) monopoly scheduling model along with a differentiation of consumers by their value of time similar to the one suggested in Bilotkach (2009). In the model, utility for a consumer traveling by air is given by ConsumptionSchedule delay disutility + Value of available time. Consumption is $y-p_{\text {air }}$ where $y$ is the common level of income and $p_{\text {air }}$ is the airline's fare.

Letting $H$ denote the time circumference of the circle, consumer utility then depends on expected schedule delay (defined as the difference between the preferred and actual departure times) which equals $H / 4 f$, where $f$ is number of (evenly spaced) flights operated by the airline. The Schedule delay disutility is equal to a disutility parameter $\delta>0$ times the expected schedule delay expression from above, thus equaling $\delta H / 4 f=\gamma / f$, where $\gamma \equiv \delta H / 4$. We assume that all passengers value frequency equally and thus the parameter $\gamma$ is common for all of them. Passenger heterogeneity arises here through travelers' value of time, as it is explained below.

Finally, the available time at the destination is computed as the difference between passenger's total trip time $(T)$ and the actual traveling time which depends on the distance between the origin and the destination $(d)$ and the plane's speed $(V)$, thus equaling $T-d / V$. We assume a large enough $T$ so that $T>d / V$. Thus, taking into account the traveler's specific value of time $\alpha$, the Value of available time at the destination equals $\alpha(T-d / V)$, where $\alpha$ is assumed to be uniformly distributed over the range $[0,1]$. Hence, utility from air travel is

$u_{\text {air }}=y-p_{\text {air }}-\gamma / f+\alpha[T-d / V]$.

However, consumers can also make use of an alternative surface transport mode (i.e., car) obtaining a utility of Consumption + Value of

\footnotetext{
${ }^{3}$ Additionally, unlike the US airline industry, European airline markets have been relatively under-researched (due predominantly to the lack of sufficient data).
} 


\section{دريافت فورى ـ ـ متن كامل مقاله}

\section{ISIArticles}

مرجع مقالات تخصصى ايران

ل امكان دانلود نسخه تمام متن مقالات انكليسى ل امكان دانلود نسخه ترجمه شده مقالات ل يذيرش سفارش ترجمه تخصصى $\checkmark$ ل امكان جستجو در آرشيو جامعى از صدها موضوع و هزاران مقاله ل امكان دانلود رايكان r صفحه اول هر مقاله

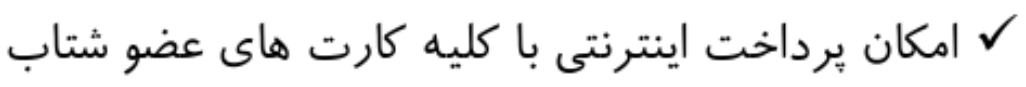
ل دانلود فورى مقاله پِ از برداخت آنلاين

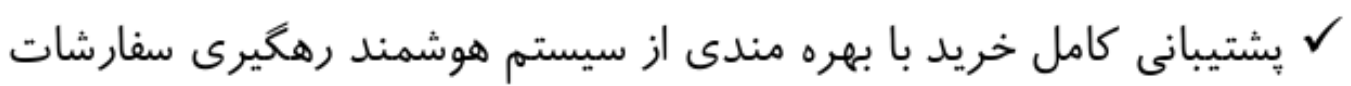

